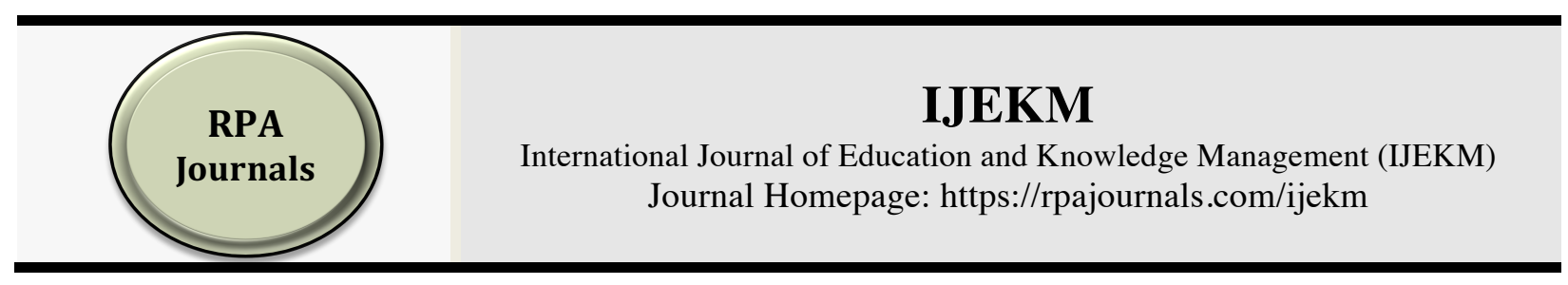

\title{
The Leadership Gym: A Proposed Undergraduate Leadership Programme for Generation $\mathrm{Z}$
}

\author{
Maria Saberi \\ Ahlia University, Bahrain
}

\begin{abstract}
This theoretical paper proposes a contemporary undergraduate leadership programme called the 'Leadership Gym'. The programme is customised to cater to the digitally connected and highly kinetic generation $\mathrm{Z}$ by creating a gym-like experience where training methods are made compatible with the new generation's learning paradigm. Through a critical review of the latest literature on contemporary leadership training methods and on the most essential leadership skills for generation $\mathrm{Z}$ as well as this new generation's paradigm shift in learning styles, five intended learning outcomes (ILOs) have been extracted and designed into the proposed leadership programme, namely self-initiated behaviour, self-directed learning, emotional intelligence, team building, and design-thinking skills. This paper goes on to elaborate on the gym's management process as well as the learners' performance management methodology. In addition, detailed descriptions of the physical, cognitive, social, and emotional aspects of the Leadership Gym's design are stipulated. The design components of the Leadership Gym are also based on the review of literature in order to enrich the proposed programme.

Keywords: Leadership-Gym, Generation-Z, Undergraduate, Learner-Centred, Self-DirectedLearning, Emotional-Intelligence, Team-Building, Design-Thinking
\end{abstract}

*Corresponding author: Maria Saberi; Email: msaberi@ahlia.edu.bh DOI: https://doi.org/10.37227/IJEKM-2020-02-37

\section{Introduction}

Two of the main characteristics of generation Z (Gen-Z), those born after 1995, are being highly kinetic hands-on learners as well as being digitally 'hyperconnected' since birth, both of which have in turn led to their attainment of super-fast, six-second visual information gathering capability (Bertagni and Salvetti, 2015; Prensky, 2001; Rothman, 2016; Seemiller and Grace, 2016; Shatto \& Erwin, 2017). Therefore, the traditional hierarchy-based teacher-student lecture system has failed to achieve its pursued learning outcomes among Gen-Z learners (Swanzen, 2018). Consequentially, a digitally-based, learning-by-doing, learner-centred system equipped with fast-paced social media platforms is gradually taking over the higher education arena (Bertagni and Salvetti, 2015; Cilliers, 2017; Rospigliosi, 2019; Safitri et al., 2019; Swanzen, 2018). Such a higher education system, however, is still adapting to the new learning paradigm imposed by Gen-Z. Furthermore, this new learning pedagogy is not restricted to the technical fields of higher education. Courses related to human skills development are also adapting to the learning styles of Gen-Z. Since such a learning pedagogy is new to higher education, there are not 
many applications of human skills development programmes catered for Gen-Z's dynamic learning style. Amongst these are leadership programmes. Therefore, this paper proposes a prototype of an undergraduate leadership programme called the 'Leadership Gym', through which a detailed description of a proposed learning environment made compatible with the new generation's unique learning styles is illustrated.

For over three decades, it has been evident that people learn best when having fun (Hromek and Roffey, 2009). Therefore, when a sense of play is added to the design and delivery of the learning process, such as in games-based, experiential and self-directed learning methodologies, learning becomes natural and spontaneous (Herro and Clark, 2016; Hromek and Roffey, 2009; Mercer et al., 2017; Nousiainen et al., 2018; Sung et al., 2017). In addition, recent studies show that generation $Z$ perform best when they are made an integral part of the learning environment, being able to choose the time, space, and mode of learning (Hamalainen, Kiili and Smith, 2017; Mercer et al., 2017; Nousiainen, et al., 2018; Reigeluth, et al., 2015; Vance, 2018). Such opportunities allow, for example, learners to produce their own designed activities and games after being furnished with the programme's aim and learning outcomes (Amara and Saberi, 2018). In other words, when the teacher and learner are teamed as learning partners, motivation to learn spikes considerably (Mercer et al., 2017). This is particularly true for generation Z, among whom such partnership causes maximised learner engagement and satisfaction, which in turn enriches the quality of learning outcomes, particularly those related to employability skills (Murillo-Zamoranoa, Sáncheza and Godoy-Caballero, 2019). Such a learner-centred pedagogy is relatively new to higher education, particularly in leadership development programmes catered for Gen-Z's learning style. Therefore, the following sections propose a contemporary undergraduate leadership programme called the 'Leadership Gym'.

\section{Literature Review}

A theoretical model called 'skill-building process' developed by Vance (2018) emphasises that "adolescents are drivers of their own development" (op cit. p. 967). Supported by a volume of reviewed research related to developmental theories, Vance (2018) goes on to link between the youth being active learners and the inevitable need for them to "direct their pursuit of skills," turning the traditional role of teachers to that of facilitators who are required to allow the youth to "maintain ownership of their learning while also offering guidance" (op cit. p. 967).

The Leadership Gym furnishes a self-directed skill-building learning experience that allows learners to have a gym-like experience, except that they will be building their character instead of their skeletal muscles. This proposed leadership programme has been designed to accommodate Gen- $Z$ undergraduates currently between the ages of 17 and 25 . One reason that this age range has been targeted is that it is a critical transition phase in which both behavioural control and self-regulation mature from basic other-dependent world views to complex self-dependent life experiences (Reichelt, 2016). In addition, although this phase can be passed effortlessly for some, for many others it can be a rough start if left without coaching (Lefdahl-Davis et al., 2018). The following sections illustrate the learning outcomes, design, and operation of the Leadership Gym in greater detail.

\section{Intended Learning Outcomes (ILOs) of the Programme}

Before going into further design details, it is necessary to clarify the Leadership Gym's intended learning outcomes (ILOs). Based on a review of the latest literature on core 
leadership skills necessary for the enhancement of youth, particularly Gen-Z leadership behaviour, five learning outcomes are seen to be in line with the proposed gym's purpose. These learning outcomes are designed into several training stations similar to a sports gym that learners will pass through as teams to attain the intended leadership skills. The gym's stations follow a 'project-based learning' method that combines active team-based learning with complex problem-solving tasks (Moore, Jones and Frazier, 2017). These ILOs are as follows:

\section{Self-initiated behaviour (SIB)}

Self-initiated behaviour is known in psychology as a mental process that causes selfmotivation by facilitating a person in deciding what action to perform and when to initiate it, be it a pre-specified or self-chosen action (Kos et al., 2017). SIB sits at the very core of a mentally healthy leader, acting as a pre-requisite to all other leadership skills as it helps learners stand out in all aspects of life experiences, be they family obligations, career advancement or community engagement. Furthermore, as SIB is considered a main employability skill, its development becomes particularly essential for Gen-Z due to their having less work experience in comparison to prior generations (Schroth, 2019). Therefore, enhancing SIB through the proposed Leadership Gym would better prepare learners for the labour market.

\section{Self-directed learning (SDL)}

A consequence of SIB and another core learning outcome believed to pave the way for developing workplace competencies, self-directed learning is recognised as the ability to willingly initiate, prepare, execute, and evaluate one's own learning without the need to be guided by other people (Kos et al., 2017; Morris, 2018; Zhoc et al., 2018). Although a critical leadership characteristic, both academic and vocational educational institutions have not fully incorporated SDL into their programmes (Morris, 2018). SDL is enhanced via the proposed Leadership Gym's flipped learning problem-based design where learners decide "what is to be learnt next and how best to accomplish it" (Zhoc et al., 2018, p. 985), hence self-dependently acquiring the essential leadership skills (Tomas et al., 2019; Murillo-Zamoranoa, Sáncheza and Godoy-Caballero, 2019).

\section{Emotional Intelligence (EI)}

Emotional Intelligence (EI) was originally presented by Salovey and Mayer as a scientific concept in 1990, when they defined the term as "the ability to monitor one's own and others' feelings and emotions, to discriminate among them and to use this information to guide one's thinking and actions" (Salovey and Mayer, 1990, p. 189). Since then, EI has been claimed as a prerequisite to several intrapersonal and interpersonal skills particularly related to leadership. Antonakis, Ashkanasy and Dasborough (2009), for example, conclude in their theoretical research that leadership is an "emotion-laden process," and a "leader who can manage his/her own emotions and have empathy for others will be more effective in the workplace" (op cit., p. 252). Furthermore, empathy, known for its positive impact on subjective wellbeing, an affective reaction to one's life satisfaction, has also been found as a core component of EI, which in turn helps promote altruistic tendencies and prosocial behaviour (Fry and Runyan, 2018; Goleman, 1996; Huang, Shi and Liu, 2018). 
According to Schroth (2019), Gen-Zers have reported that stress hinders their ability to take on leadership responsibilities and that this particular generation has scored the highest worldwide in reporting cases of anxiety, consequently reducing their subjective wellbeing. Through fostering altruistic behaviour, it is believed that EI's impact on enhancing positive subjective well-being is heightened (Huang, Shi and Liu, 2018). For this reason, the Leadership Gym enhances its members' ability to cope with stress through activities and projects that require altruistic behaviour.

Another well-known set of skills affected by EI is communication skills (Nouri et al., 2014). In this regard, Schroth (2019) argues that due to communicating digitally more than $70 \%$ of the time, Gen-Zers have missed out on the fundamental rules of face-to-face conversation, namely listening skills, building relationships, and resolving conflicts. Therefore, during their training, members of the Leadership Gym will be placed in teams where they will need to complete tasks and resolve given problems though face-to-face communication as they move through the gym's stations.

Furthermore, research by Zhoc et al. (2018) has shown that those who score high EI levels are more self-directed due to their ability to regulate their own emotions and generate positive emotions, leading to a self-motivated disposition.

\section{Team-building skills}

Together with communication skills, team building fosters knowledge sharing, and in turn causes a positive impact on the team members' creativity, which when maintained, can significantly impact organisational survival, effectiveness and ultimately, its success (Dong et al., 2016; Gupta and Banerjee, 2016). For Gen-Zers, the ability to build and maintain creative teams is a cornerstone in building today's economy (Rothschild, 2016). This is mainly because of the changing workplace decision-making process from the traditional hierarchical approach of the bureaucratic organisational structure to a 'consensusorientated' team-based structure, where a "fluid and participatory division of labour" is practiced in workgroups, making them the most efficient in their decision-making process (Leach, 2016).

Working together in teams while passing through the proposed Leadership Gym's stations, the learners' sense of community and team-building skills are developed. At each station, team members work together on project-based tasks (Moore, Jones and Frazier, 2017) where consensus-based decisions are continuously required, mainly in regard to the design of their next leadership station as well as the related learning outcomes they wish to obtain.

\section{Design-thinking skills}

Micheli et al. (2019) conducted a comprehensive review of literature on design thinking. They concluded that problem solving, creativity, and innovation, as well as analytical and intuitive thinking were the constructs and outcomes of design thinking. Although a common definition of design thinking is not yet available, due to its being a fairly new construct according to Micheli et al., a definition relevant to the purpose of the proposed leadership programme has been introduced. Therefore, design thinking is considered here an analytical-intuitive thinking skill through which iteration and experimentation (trialand-error) learning is conducted to solve problems in a creative manner in order to produce innovated solutions, leading to observable behavioural change (Mercer et al., 2017). 
Encouraging design thinking can help Gen-Zers become autonomous decisionmakers and self-directed learners (Schroth, 2019). The ambiguity of the proposed Leadership Gym's tasks at every station simulates the uncertain situations that can often crop up in the workplace, and therefore, is believed will help learners enhance their designthinking skills and its accompanying competencies.

\section{Gym's Management}

At the Leadership Gym, the programme is managed by two types of trainers. These are coaches and facilitators. Coaches conduct the actual leadership training and meet with the learners physically in the gym. Coaching is known as a tailored learning and development process that uses a collaborative relationship in achieving outcomes pursued by the coachee (Smither, 2011). Such a learning process would work very well for Gen-Zers as they prefer a collaborative learning rather than a pedantic approach (Mercer et al., 2017; Schroth, 2019). Furthermore, Lefdahl-Davis et al. (2018) advise the embedding of life coaching into higher education as it is proven to "help students effectively manage the plethora of stressors during a key time of transition and growth" (op cit., p. 71).

Facilitators, on the other hand, are recruited into the gym as volunteers. They stay in touch with the learners digitally $24 \times 7$ using social media groups throughout the duration of their programme following up on the learners' progress, addressing their training needs, and sharing all electronic learning materials. The facilitation process follows the flipped learning approach, whereby the learner and teacher roles are reversed as learners prepare for and manage their own learning experience outside the classroom through digital apps and the teacher's role becomes more that of assistant who encourages creative thinking through activities conducted by the learners during class time (Mercer et al., 2017; Rospigliosi, 2019; Tomas et al., 2019). During gym time, facilitators, who could be graduate members of the Leadership Gym, also assist the coach by shadowing them. This way, each facilitator simultaneously trains to be a future coach.

At the Leadership Gym, learners are considered members of the gym. Therefore, from here onwards in this paper, learners will be addressed as members. The Leadership Gym is an ongoing leadership programme that is managed pretty much like a gym, where members/learners can join at any time of the year and choose to attend from a selection of timeslots (morning, afternoon, and evening) in order to assure availability of the coach on shift. Once members join the Leadership Gym and are designated to their teams, each participating team moves through the gym's stations by collectively selecting the ILO they wish to enhance next and pre-designing a relevant activity, task or game to the selected ILO every time. During the designing of activities as well as their application, each team works with their assigned coach, who will make sure the targeted ILOs are met. This is repeated through the rest of the stations and is coupled with frequent performance assessments until all five ILOs are maintained, whereby members are considered to have completed their leadership programme. However, the programme does not end here. Upon completion, each member is given a choice of returning to the Leadership Gym as a volunteer facilitator and work their way to becoming a coach.

Furthermore, members' leadership behavioural progress is formatively assessed on a weekly basis through one-to-one feedback sessions where members are engaged in the feedback process through peer and self-evaluation as well as receiving feedback from their coaches (Moore, Jones and Frazier, 2017). Formative assessment is known for its effect when behavioural aspects are being developed and evaluated through an ongoing process

International Journal of Education and Knowledge Management (IJEKM) 
(Mash et al., 2019). Such assessments have been found more effective in enhancing GenZers' skills than traditional standardised summative assessments particularly for outcomebased education (Moore, Jones and Frazier, 2017). During these feedback sessions, members express their observation of their own areas of progress and discuss these with their coach and together plan to achieve the next suitable learning outcome.

\section{Leadership Gym Design}

The following sections elaborate on the proposed physical, cognitive, social, and emotional aspects of the Leadership Gym's design:

\section{Physical aspects}

The Leadership Gym is to be housed within a large open space with a dome-shaped glass ceiling and a gym-themed interior. Instead of fixed concrete walls, this gym will have mobile partition walls containing large sliding glass doors. These partitions help members design their own creative layout for the stations according to the ILOs being covered, thereby enforcing self-directed learning. The gym will be equipped with multipurpose furniture, which will be used as required by members and coaches for the different stations' functions. The gym will have plenty of natural lighting during the day in addition to natural-like lighting installed for night sessions.

Furthermore, as illustrated earlier, the suggested five learning outcomes are interdependent and so, will be delivered as sets of ILOs rather than a single learning outcome per station. In addition to non-digital-based resources, several stations are equipped with digital resources for members to select from while they design their activities. For example, a virtual reality (VR) simulator will be made available at one of the gym's stations. This VR station is to be used to coach members through multiple ILOs, mainly self-directed learning and design-thinking skills. Furthermore, smart phones are a must at the Leadership Gym, as they will be used to access online digital content for elearning purposes during gym time. Fry and Runyan (2018) have suggested ways of using smartphones to "redirect our attention to those around us," which, consequently, help people behave empathetically towards others and in turn "nurture a compassionate disposition" (p. 1).

\section{Cognitive, social, and emotional aspects}

As explained earlier, members decide together as a team which ILOs they would like to achieve first and in which sequence. At each station, all members will have to interact with each other, discuss, and use their leadership skills to complete the given game-based activities. These activities demand increased interaction amongst members, which naturally aids in enhancing members' adaptiveness and team-building and communication skills (Hamalainen, Kiili and Smith, 2017).

It is important to mention that the gym's operation is briefly explained by the facilitator as teams move through the gym's stations, leaving members to work out the details together. This ambiguity encourages a 'discovery' based learner-centred system (Safitri et al., 2019), which is believed to produce members' feelings of 'ownership' of their learning experience (Hamalainen, Kiili and Smith, 2017), in turn leading to enhanced self-directed learning. Furthermore, the gym creates a common experience within the participating teams and instils values of team spirit as they move together through their leadership stations. In addition, they learn altruism through giving back after graduating by 
becoming a facilitator and experiencing the pleasure of helping people develop. Each team learns to create a sense of family and community engagement after spending the time working together through the challenging stations.

In addition, emotional development is an integral component of the Leadership Gym where it is one of the programme's ILOs enhanced through developing members' emotional intelligence (EI), which in turn helps enhance other relevant learning outcomes such as communication skills, altruism, and self-directed learning. The gym will provide an environment of joy, fun, and empowered learning. Such an environment motivates members to return and continue as leadership facilitators and coaches.

\section{Research Methodology}

A critical literature review methodology, also called "integrative literature review" (Snyder, 2019) has been adopted by this theoretical research paper. Latest literature on contemporary leadership training methods and the most essential leadership skills for generation $\mathrm{Z}$ as well as the new generation's paradigm shift in learning styles, was analysed with the aim to extract the most prominent generation- $Z$ leadership skills advised by the body of current literature and then integrate these skills into the design of the proposed leadership programme where they were presented as essential intended learning outcomes (ILOs). This critical review also aided in constructing the physical, cognitive, social, and emotional aspects of the Leadership Gym's design. Integrative literature reviews are known to 'address new, emerging topics' such as this one, therefore contributing in the expansion of the theoretical foundation of the specific topic as it develops by proposing 'preliminary conceptualizations, rather than reviewing old models' (Snyder, 2019, pp.335336).

\section{Research Limitation and Future Direction}

Due to the proposed Leadership Gym being designed based mainly on critical review of latest literature, although backed up with the researcher's insight gained from over a decade of experience in designing and enhancing undergraduate leadership courses, the scope of the presented research is limited to a more presuming approach through a theoretically based proposal. Therefore, future empirical testing of the proposed leadership programme is essential to shed further light on the current inquiry in order to establish a more grounded model which would verify the programme's feasibility and gain the support needed to be launched.

\section{Conclusions}

Much research has proven the impact of modern learning techniques, such as the projectbased experiential learning, the problem-based learning, and game-based learning, which basically follow a flipped education strategy where students become self-directed learners and educators play the role of coach or facilitator, such as Mercer et al. (2017), Moore, Jones and Frazier (2017), Murillo-Zamoranoa, Sáncheza and Godoy-Caballero (2019), Rospigliosi (2019), Tomas et al. (2019), and Zhoc et al. (2018). However, no one single programme has been designed in a way that serves the changed learning needs of generation $\mathrm{Z}$, particularly for developing sustainable leadership skills, which would be of immediate use in today's work world. This paper has proposed a unique design of an undergraduate leadership programme, customized in all its aspects, to the paradigm shift in 
undergraduate learning caused by generation Z. The Leadership Gym has been designed based on both latest literature as well as over 15 years of experience in designing and enhancing undergraduate leadership courses. Although the idea of gym stations and the five proposed ILOs have already been simulated in regular undergraduate classrooms by the researcher, further empirical testing will be required to prove the programme's feasibility and gain the support needed to launch it.

\section{Acknowledgment}

This paper was presented at the Applied Research International Conference on Education \& Professional Development (ARICEPD), 2020 Cambridge, United Kingdom (UK).

\section{References}

Amara, A. B. and Saberi, M. (2018), "Enhancing learning outcomes achievement in higher education using gaming strategies: the case of business courses", in ECGBL18: The 12th European Conference on Games Based Learning proceedings of the conference in Sophia Antipolis, France, pp. 923-931.

Antonakis, J., Ashkanasy, N. M. \& Dasborough, M. T. (2009). Does leadership need emotional intelligence? The Leadership Quarterly, 20, 247-261.

Bertagni, B. \& Salvetti, S. (2015). Dealing with complexity in a simple way: how visualization boosts understanding in learning process. The $\mathrm{Z}$ generation case. Sociologia del lavoro, 137, 201-215.

Cilliers, E. J. (2017). The challenge of teaching generation Z. International Journal of Social Sciences, Special Issue, 3(1), 188-198.

Dong, Y. et al. (2016). Enhancing employee creativity via individual skill development and team knowledge sharing: influences of dual-focused transformational leadership. Journal of Organisational Behaviour, 38(3), 439-459.

Fry, B. N. \& Runyan, J. D. (2018). Teaching empathic concern and altruism in the smartphone age. Journal of Moral Education, 47(1), 1-16.

Goleman, D. (1996), Emotional intelligence. London, UK: Bloomsbury.

Gupta, R. \& Banerjee, P. (2016). Antecedents of organisational creativity: a multi-level approach. Business: Theory and Practice, 17(2), 167-177.

Hamalainen, R., Kiili, C. \& Smith, B. E. (2017). Orchestrating 21st century learning in higher education: a perspective on student voice. British Journal of Educational Technology, 48(5), 1106-1118.

Herro, D. \& Clark, R. (2016). An academic home for play: games as unifying influences in higher education. On the Horizon, 24(1), 17-28.

Hromek, R. \& Roffey, S. (2009). Promoting social and emotional learning with games "it's fun and we learn things". Simulation \& Gaming, 40(5), 626-644.

Huang, J., Shi, H. \& Liu, W. (2018). Emotional intelligence and subjective well-being: altruistic behaviour as a mediator. Social Behaviour and Personality, 46(5), 749758.

Kos, C. et al. (2017). Neural basis of self-initiative in relation to apathy in a student sample. Scientific Reports, 7(3264), 1-10.

Leach, D. K. (2016). When freedom is not an endless meeting: a new look at efficiency in consensus-based decision making. The Sociological Quarterly, 57(1), 36-70. 
Lefdahl-Davis, E. M. et al. (2018). The impact of life coaching on undergraduate students: a multiyear analysis of coaching outcomes. International Journal of Evidence Based Coaching and Mentoring, 16(2), 69-83.

Mash, R. et al. (2019). Improving the quality of clinical training in the workplace: implementing formative assessment visits. South African Family Practice, 61(6), 264-272.

Mercer, T. G. et al. (2017). The use of educational game design and play in higher education to influence sustainable behaviour. International Journal of Sustainability in Higher Education, 18(3), 359-384.

Micheli, P. et al. (2019). Doing design thinking: Conceptual review, synthesis, and research agenda. Journal of Product Innovation Management, 36(2), 124-148.

Moore, K., Jones, C. \& Frazier, R. S. (2017). Engineering education for generation Z. American Journal of Engineering Education, 8(2), 111-126.

Morris, T. H. (2018). Vocational education of young adults in England: a systemic analysis of teaching-learning transactions that facilitate self-directed learning. Journal of Vocational Education \& Training, 70(4), 619-643.

Murillo-Zamoranoa, L. R., Sáncheza, J. A. L. \& Godoy-Caballero, A. L. (2019). How the flipped classroom affects knowledge, skills, and engagement in higher education: effects on students' satisfaction. Computers \& Education, 141, 1-18.

Nouri N. et al. (2014). Relationship between emotional intelligence and communication skills among high school students in Hamadan based on the theory of social support. Journal of Education and Community Health, 1(3), 38-46.

Nousiainen, T. et al. (2018). Teacher competencies in game-based pedagogy. Teaching and Teacher Education, 74, 85-97.

Prensky, M. (2001). Digital natives, digital immigrants part 1. On the Horizon, 9(5), 1-6.

Reichelt, A. C. (2016). Adolescent maturational transitions in the prefrontal cortex and dopamine signalling as a risk factor for the development of obesity and high fat/high sugar diet induced cognitive deficits. Frontiers in Behavioural Neuroscience. 10(189), 1-17.

Reigeluth, C. M. et al. (2015). Personalized integrated educational system: technology functions for the learner-centered paradigm of education. Journal of Educational Computing, 53(3), 459-496.

Rospigliosi, P. (2019). The role of social media as a learning environment in the fully functioning university: preparing for generation $\mathrm{Z}$. Interactive Learning Environments, 27(4), 429-431.

Rothman, D. (2016). A tsunami of learners called generation Z. Maryland Police and Correctional Training Commissions. Retrieved August 23 2019, from http://www.mdle.net/Journal/A_Tsunami_of_Learners_Called_Generation_Z.pdf.

Rothschild, J. (2016). The logic of a co-operative economy and democracy 2.0: recovering the possibilities for autonomy, creativity, solidarity, and common purpose. The Sociological Quarterly, 57(1), 7-35.

Safitri, D. A., Umamah, N. \& Sumardi (2019), "Accelerated learning integrated by discovery learning in history course: how Z generation learn", proceedings of the conference in IOP Conference Series: Earth and Environmental Science, 243 012151.

Salovey, P. \& Mayer, J. D. (1990). Emotional intelligence. Imagination, Cognition, and Personality, 9(3), 185-211. 
Schroth, H. (2019). Are you ready for Gen Z in the workplace? California Management Review, 61(3), 5-18.

Seemiller, C. \& Grace, M. (2016), Generation Z goes to college. John Wiley \& Sons.

Shatto, B. \& Erwin, K. (2017). Teaching millennials and generation Z: bridging the generation divide. Creative Nursing, 23(1), 24-28.

Smither, J. W. (2011). Can psychotherapy research serve as a guide for research about executive coaching? An agenda for the next decade. Journal of Business and Psychology, 26(2), 135-145.

Snyder, H. (2019). Literature review as a research methodology: an overview and guidelines. Journal of Business Research, 104, 333-339.

Sung, H. et al. (2017). Experiencing the analects of Confucius: an experiential game-based learning approach to promoting students' motivation and conception of learning. Computers \& Education, 110, 143-153.

Swanzen, R. (2018). Facing the generation chasm: the parenting and teaching of generations Y and Z. International Journal of Child, Youth and Family Studies, 9(2), 125-150.

Tomas, L. et al. (2019). Are first year students ready for a flipped classroom? A case for a flipped learning continuum. International Journal of Educational Technology in Higher Education, 16(5), 1-22.

Vance, F. (2018). Understanding adolescents' skill-building in the after-school context. Youth \& Society, 50(7), 966-988.

Zhoc, K. C. H., Chung, T. S. H. \& King, R. B. (2018). Emotional intelligence (EI) and self-directed learning: examining their relation and contribution to better student learning outcomes in higher education. British Educational Research Journal, 44(6), 982-1004. 